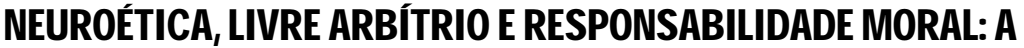

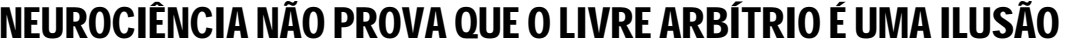

\section{Cinara Nahra}

\author{
Universidade Federal do Rio Grande do Norte/CNPQ
}

Resumo: Com o notável avanço da neurociência na última década, especialmente com a realização de experimentos neurocientíficos que tem ajudado a lançar luzes em questões tradicionais da filosofia como altruísmo, generosidade e moralidade, foi também levantada a hipótese de que a neurociência provaria que o livre arbítrio é uma ilusão. Um dos experimentos que corroboraria esta hipótese está amplamente discutido no artigo "Unconscious determinant of free decisions in the human brain" assinado por um grupo de neurocientistas liderados por C. Soon e H. Heinze e publicado na revista Nature em 2008. Nosso objetivo aqui é mostrar: a) que o referido experimento, cujos resultados são descritos no artigo, não pode ser usado como evidencia que o livre arbítrio não existe; e b) levantar algumas outras hipóteses interpretativas para os resultados da pesquisa. Finalmente discutimos 0 que os estudos recentes de neurociência podem nos ensinar sobre responsabilidade moral.

Palavras-chave: neuroética, neurociência, livre arbitrio, responsabilidade moral.

Abstract: With the remarkable advance of neuroscience in course since the past decade and the performance of neuroscientific experiments that have shed some lights in traditional philosophical questions such as altruism, generosity and morality, it has been suggested the hypothesis that neuroscience proves that free will is an illusion. One of the main experiments that would corroborate this hypothesis is discussed in the article "Unconscious determinant of free decisions in the human brain" signed by a group of neuroscientists lead by $\mathrm{C}$. Soon and $\mathrm{H}$. Heinze and published in Nature in 2008. Our aim here is to show that a) the results of this experiment can not be used as evidence that free will does not exist and $b$ ) put forward others interpretative hypothesis for the results of this study. Eventually I discuss what recent studies on neuroscience can teach us about moral responsibility.

Keywords: neuroethics, neuroscience, free will, moral responsibility. 
A neurociência prova que o livre arbítrio não existe? O problema do livre arbítrio é um dos problemas filosóficos mais clássicos de todos os tempos. Entretanto com o extraordinário desenvolvimento da neurociência no início do milênio, particularmente com o uso de técnicas de fMRI (functional magnetic resonance imaging) para observar o cérebro humano, muitas das perguntas que historicamente foram discutidas prioritariamente pela filosofia, podem ser respondidas pela neurociência, ou ao menos, podem começar a ser respondidas por esta, e estas respostas, apontam alguns autores, estaria pendendo para o lado da constatação de que o livre arbítrio é uma ilusão. Sam Harris é um dos autores mais radicais no entendimento do livre arbítrio como sendo uma ilusão ${ }^{1}$. Já para Churchland ${ }^{2}$, na medida em que a neurociência vai descobrindo os mecanismos que regulam nossas escolhas e nosso comportamento social não podemos deixar de perguntar se nós verdadeiramente escolhemos qualquer coisa. Já Adina Roskies ${ }^{3}$ observa também que recentes desenvolvimentos em neurociência levantam a questão sobre se o entendimento de como o cérebro gera comportamentos iria destruir (undermine) nossa visão sobre livre arbítrio e sobre responsabilidade moral.

Há três trabalhos relativamente recentes, de neurociência, que causaram certo frenesi na mídia nacional e internacional dedicada à divulgação científica, e que de certo modo poderiam corroborar a ideia de que o livre arbítrio não existe. Os trabalhos são todos de um grupo de pesquisadores vinculados ao Instituto Max Planck e todos eles se propõem a contribuir para a discussão sobre se, afinal, nós somos ou não livres, através de experimentos. Antes de analisar os resultados dos experimentos, vamos verificar o que dizem estes autores. Soon ${ }^{4}$ nos diz que

a impressão que nós somos capazes de escolher livremente entre possíveis cursos de ação é fundamental para nossa vida mental. Entretanto tem sido sugerido que esta experiência subjetiva da liberdade não é mais do que uma ilusão e nossas

\footnotetext{
${ }^{1}$ HARRIS, Sam. New York: Free Press, 2012.

2 CHURCHLAND, Patrícia. "Do we have free will?". Disponível em: http://philosophyfaculty.ucsd. edu/faculty/pschurchland/papers/newscientist06dowehavefreewill.pdf\#page=1\&zoom=auto,0,800. Acessado em 31/10/2013 de New Scientist.com News service.

3 ROSKIES, Adina. "Neuroscientific challenges to free will and responsibility". In: Trends in Cognitive Sciences, vol.10, n.9, 2008, p. 419-423.

4 SOON, Chun; BRASS, Marcel; HEINZE, Hans-Jochen; HAYNES, John Dylan. "Unconscious determinant of free decisions in the human brain". In: Nature, vol. 11, n. 5, 2008, p. 543-545.
} 
ações são iniciadas por processos mentais inconscientes muito antes de que nos tornemos conscientes de nossa intenção de agir.

Já Haynes, que também assina o artigo mencionado, em outro artigo ${ }^{5}$ afirma que

a demonstração direta que a atividade cerebral prediz o resultado das decisões antes que elas atinjam a consciência tem o poder persuasivo adicional de convencer as pessoas que elas são mais previsíveis que eles pensam ser.

Finalmente em $2011^{6}$, Bode afirma que

como humanos temos a habilidade de escolher conscientemente nossas ações assim como o tempo de praticálas. Tem sido postulado, entretanto, que esta experiência subjetiva da liberdade pode ser apenas uma ilusão, e que mesmo nossos objetivos e motivações podem operar fora de nossa consciência.

Mas o que, exatamente, são estes experimentos e o que eles nos dizem? $\mathrm{Na}$ realidade eles são revisões do experimento clássico de Benjamin Libet, porém utilizando equipamentos para análise cerebral muito mais avançados, como o fMRI. O experimento é assim descrito ${ }^{7}$ :

Os pesquisados eram convidados a fixar sua atenção em uma tela onde várias letras eram apresentadas. Quando eles quisessem eles deveriam livremente escolher entre dois botões, um operado pelo dedo indicador direito e outro pelo esquerdo e imediatamente pressioná-lo. Paralelamente eles deveriam lembrar a letra que aparecia na tela quando sua decisão motora foi conscientemente feita. Depois que os pesquisados pressionassem o botão livremente escolhido, um

\footnotetext{
${ }^{5}$ HAYNES, John D. "Decoding and predicting intentions". In: Ann. N.Y. Acad. Sci., 1224, 2011, p. 9-21. ${ }^{6}$ BODE, Stefan; HANXI HE, Anna; SOON, Chun Siong; TRAMPEL, Robert; TURNER, Robert; HAYNES, John Dylan. "Tracking the Unconscious Generation of Free decisions Using Ultra-High Field fMRI". In: Plos One, vol. 6, n. 6, 2011, p.1-13.

7 SOON, Chun et all, Op. cit., p. 543.
} 
mapa de respostas com quatro escolhas aparecia na tela e os pesquisados então indicavam quando eles tomaram sua decisão motora selecionando a letra que aparecia na tela no momento em que tomaram sua decisão, apertando um segundo botão.

Os autores do estudo, então, em suas conclusões, afirmam que duas regiões específicas no córtex frontal e parietal do cérebro humano tinham considerável informação que "preveria" o resultado de uma decisão motora que o pesquisado ainda não tinha conscientemente tomado. Isso sugere que quando a decisão do sujeito atingiu a consciência, ela tinha sido influenciada por atividade cerebral inconsciente de ate 10 segundos. Os autores observam que seus resultados avançam substancialmente em relação a estudos prévios mostrando que as primeiras informações preditivas estão codificadas em regiões específicas do córtex frontopolar e parietal. Em 2011 os resultados do estudo foram replicados por Bode $^{8}$ mostrando que intenções motoras estavam codificadas no córtex frontopolar (FPC) até $7 \mathrm{~s}$ antes dos participantes estarem conscientes de suas intenções, ratificando a conclusão de que o córtex frontopolar é parte de uma rede de regiões cerebrais que molda decisões conscientes muito antes delas atingirem a consciência.

No entanto a análise mais aprofundada dos resultados descritos no experimento, e a que mais nos interessa do ponto de vista filosófico, vem de Haynes ${ }^{9}$, que reafirma que a primeira região a "prever" a decisão era a FPC/Brodmann área 10 (BA10), conjuntamente com uma segunda região preditiva o Córtex Parietal (PC), e que a informação preditiva estava já presente 7 segundos antes dos sujeitos decidirem. Haynes também observa que as descobertas dos padrões de atividade preditivos em BA10 são interessantes porque esta área não é normalmente discutida em conexão com o livre arbítrio, mas que embora BA10 tenha raramente sido implicada na preparação de ações voluntárias, uma comparação direta entre diferentes regiões cerebrais revela que a região cortical que exibe os primeiros sinais antes do movimento voluntário é a FPC e que, além disso, acredita-se que BA10 é a área que mais desproporcionalmente tenha crescido em tamanho nos humanos, comparativamente com os primatas não humanos. Discutindo

\footnotetext{
${ }^{8}$ BODE et all, Op. cit.

9 HAYNES, J. D. Op. cit.
} 
diretamente as implicações para o livre arbítrio, Haynes reafirma que: 1) O estudo referido mostra que o cérebro pode começar a inconscientemente preparar as suas decisões vários segundos antes que ela atinja a consciência; o que as descobertas salientam é que uma cascata de processos cerebrais inconscientes que iniciam no pré-frontal e no PC do cérebro aparecem por muitos segundos e preparam decisões subjetivamente livres. A partir daí Haines observa que: 2) os estudos, tanto os do seu grupo, quanto os de Libet, contrariam uma intuição específica em relação ao livre arbítrio, que ele chama da intuição psicológica ingênua, de que na hora que tomamos a decisão o resultado desta decisão é livre no sentido de não ser predeterminado por atividade cerebral anterior. Para Haynes a demonstração direta que a atividade cerebral prediz os resultados de decisões antes que elas atinjam a consciência tem o poder persuasivo adicional de convencer as pessoas de que elas são mais previsíveis do que elas acreditam ser.

Observe-se, entretanto, que enquanto a afirmação 1 é descritiva, e descreve objetivamente os resultados do experimento, a afirmação 2 é valorativa e reflete um entendimento do autor que não necessariamente decorre do experimento, e especialmente, argumentarei, não apreende $o$ sentido real de liberdade e livre arbítrio. Afirma Haynes que a visão ingênua pressupõe que só é livre o que não é determinado pelo cérebro, mas isto sim é ter uma visão ingênua sobre o que seja o livre arbítrio, já que certamente as concepções sobre o livre arbítrio mais razoáveis não pressupõem que o livre arbítrio exista independentemente de nosso cérebro ${ }^{10}$. Haynes sim, parece ter uma visão ingênua sobre o que significa ser "determinado pela atividade cerebral” já que parece pressupor aqui que o cérebro é uma entidade (ou um órgão) separado do eu, existindo "eu" e distintamente de mim, o "meu

\footnotetext{
10 NAHMIAS, Eddy. "Scientific Challenges to Free Will". In: O'CONNOR, Timothy e SANDIS, Constantine (ed). A Companion to the Philosophy of Action. UK: Blackwell, 2010, p. 345-356. Neste artigo, Nahmias argumenta que muitos cientistas simplesmente assumem que a premissa $D$ (que free will requer que determinismo seja falso) é verdadeira, ignorando uma substancial literatura filosófica que suporta a tese que o livre arbítrio não requer a falsidade do determinismo. Talvez estes cientistas tomem 0 incompatibilismo como sendo senso comum mas essa pressuposição é controversa. No artigo "Is neuroscience the death of free will?" acessivel em http://opinionator.blogs.nytimes.com/2011/11/13/isneuroscience-the-death-of-free-will/, Nahmias também argumenta que a neurociência não significa o fim do livre arbítrio e reitera que o problema principal com os cientistas que defendem esta visão é que eles estão empregando uma noção flawed ("furada") de livre arbítrio. Uma vez que usemos uma noção mais apropriada de livre arbítrio o argumento pode ser reescrito. Ao invés de mostrar que o livre arbítrio é uma ilusão, a neurociência e a psicologia podem na realidade nos ajudar a entender melhor como ele funciona.
} 
cérebro", que ao apresentar atividade preditiva inconsciente no processo de decisão, mostra que eu não sou livre para decidir. Ora! Mas não seria essa uma pressuposição quase dualista ${ }^{11}$ que separa os processos inconscientes que ocorrem no meu cérebro daquilo que sou "eu", como se os processos inconscientes não fizessem parte do que somos? Parece que Haynes aqui está em linha com o pensamento de Sam Harris ${ }^{12}$ que ao citar estes experimentos afirma que estas descobertas são difíceis de reconciliar com o sentimento de que somos os autores conscientes de nossas ações. Para Harris alguns momentos antes de que tenhamos consciência do que vamos fazer, um tempo que aparece a nós como se fôssemos livres para decidir o que quisermos, mas no qual apenas nos tornamos conscientes de nossa decisão e acreditamos que estamos no processo de toma-la, nosso cérebro já determinou o que faremos.

Entretanto, observe que, contrariamente ao que pensa Harris, mesmo que estivesse provado que o nosso cérebro determina o que iremos fazer alguns segundos antes que tenhamos consciência disto (o que, veremos a seguir, é discutível) o fato de que nós já teríamos escolhido algo antes de ter consciência disto não faz com que esta decisão não seja livre. Os mecanismos e elementos inconscientes ou não conscientes que fazem parte dos nossos processos decisórios são partes do nosso eu, e são indissociáveis da nossa estória de vida. As decisões que livremente tomamos são também influenciadas por estes mecanismos, e isso não as torna menos livres. Há inúmeros exemplos disto, mas darei aqui apenas um. Há pessoas que, como sabemos, tendem a repetir certos comportamentos em suas relações afetivas, ou mesmo que tendem a buscar parceiros (ou parceiras) que muito se parecem entre si, as vezes inclusive fisicamente. Nem sempre esta procura é consciente, na maioria das vezes é totalmente inconsciente, mas acontece. Diríamos então que João ao namorar Maria, que na realidade muito se parece com sua antiga namorada Antonia, ou mesmo com sua mãe Joana, não escolheu sua namorada livremente porque processos inconscientes operaram na escolha? Ora! João decidiu-se por uma moça entre centenas de

${ }^{11}$ KEEFNER, Kurt. Free Will. A Response to Sam Harris. Kindle edition: 2012. Ele observa que quase ninguém mais acredita no dualismo cartesiano, mas alguns vestígios dele persistem na crença que uma pessoa é constituída de consciência (o eu verdadeiro) e algo mais, sendo este algo mais o corpo, o cérebro, o inconsciente ou algo similar. Harris provavelmente não classificaria a si próprio como dualista, mas ele acredita neste modelo. Para Keefner o que Harris está dizendo é que o eu é pura consciência.

12 HARRIS, Op. cit. 
moças possíveis, uma moça eu evidentemente também o quis, e assim é claro que a escolha de João foi livre. Se Maria não tivesse querido João ele continuaria livre para escolher Maria, apenas que, neste caso, provavelmente estaria frustrado por um amor não correspondido, mas ainda assim continuaria livre para ou desistir de Maria, ou tentar conquistá-la. Esta decisão, por sua vez, também será, provavelmente, influenciada por mecanismos inconscientes, mecanismos estes que não surgiram ao acaso, fazem parte da estória de vida de João, e não o tornam menos livre. Ao contrário, estes mecanismos inconscientes fazem parte também do que significa ser João, e provavelmente se construíram de um modo absolutamente único para João e para qualquer ser humano. Como então dizer que João, que sempre escolhe o mesmo tipo de namoradas, não é livre para fazer suas escolhas? O que significaria dizer que "seu cérebro escolheu antes que ele tivesse consciência da escolha?”. Não significa nada além de dizer que "mecanismos inconscientes que operam no cérebro de João, influenciaram na decisão tomada pelo cérebro de João", ou seja, "mecanismos inconscientes presentes em João operaram na decisão de João", ou apenas "o inconsciente de João atuou na decisão de João". Isto não significa que João não é livre, significa, no máximo, que talvez tenhamos de dar mais ouvidos a Sigmund Freud!

Com isso retomo e finalizo o ponto que me parece fundamental de ser ressaltado. $O$ passo de Haynes no artigo, passando daquilo que é resultado de uma experiência, e portanto apenas descritivo em 1 para o que é avaliativo em 2 é dedutivamente questionável, sendo fruto de uma concepção sobre livre arbítrio que é problemática, e que talvez não valha a pena sustentar, ou aceitar, já que ao não ser capaz de incorporar motivos inconscientes como envolvidos na cadeia do processo de escolha não apreende a riqueza da experiência e do fenômeno que é a liberdade humana.

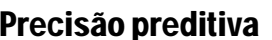

Dito isto, gostaria de chamar a atenção para outro aspecto do artigo de Haynes. Ele observou que a precisão preditiva em BA/10 e no Córtex Parietal, embora estatisticamente significativa, atingiu apenas $10 \%$ acima do nível de acaso. Segundo ele mesmo observa ${ }^{13}$, pelo critério de precedência

${ }^{13}$ HAYNES, J. H. Op. cit., p.16. 
temporal não há dúvida que os dados demonstram que uma atividade cerebral pode prever uma decisão bem antes de que ela atinja a consciência, mas uma questão diferente é o que ele chama de critério da conexão constante. Uma conexão constante requer que a decisão possa ser prevista a partir de uma atividade cerebral anterior com 100\% de precisão. A previsão de decisões a partir da atividade cerebral, afirma Haynes, é estatisticamente confiável, mas longe de ser perfeita. A acurácia preditiva de por volta de $60 \%$ (que é significativa, mas somente $10 \%$ acima do acaso) pode ser melhorada, mas mesmo sob condições ótimas, está longe de 100\%. Haynes então observa que há uma diferente interpretação possível, qual seja, a de que a falta de acurácia simplesmente reflete o fato que processos neurais anteriores podem somente ser parcialmente preditivos do resultado da decisão. Neste caso os sinais teriam a forma de sinais inclinantes que influenciam a decisão até um certo grau, mas adicional influencia, posterior, pode ainda cumprir um papel na modulação da decisão. Assim, sinais neuronais em BA10 e PC não seriam totalmente preditivos. Portanto, diz Haynes, até que uma acurácia preditiva perfeita tenha sido atingida em um experimento, ambas interpretações, predição incompleta e determinação incompleta, permanecem possíveis.

Vamos então avaliar esta possibilidade interpretativa aberta pelo próprio Haynes. A ausência de acurácia preditiva de 100\% implica que há casos aonde a previsão de uso do botão direito ou esquerdo através de padrões de atividades não conscientes no cérebro falha. No momento não é possível determinar se isto é devido ao equipamento utilizado ou a uma indeterminação intrínseca, no sentido de que não é possível fazer a previsão. De qualquer maneira, seja qual for a hipótese que se confirme, isto é suficiente para estabelecermos que, ao menos por estas pesquisas, não podemos dizer que somos capazes de prever sempre, através de padrões de atividade cerebral inconsciente, nossas decisões conscientes. Se então, como vimos, a previsão a partir desta atividade cerebral específica não significa que não temos livre arbítrio, o fato de que esta previsão não possa ser feita em $100 \%$ dos casos deixa ainda mais claro que, definitivamente, estes estudos por si só não provam que o livre arbítrio não existe. E se são principalmente estes estudos que estão sendo referidos como os principais estudos aventados a fim de mostrar que a neurociência provaria que o livre arbítrio não existe, então não poderíamos dizer que está provado que o livre arbítrio é uma ilusão.

Observe-se que há um elemento metodológico muito interessante em pesquisas empíricas relacionadas ao livre arbítrio. Enquanto em pesquisas 
com grandes populações, como pesquisas eleitorais ou epidemiológicas, a validade estatística é importante, com os respectivos desvios-padrão que nos permitem uma certa segurança para generalizar dados para todo o universo, no caso de pesquisas relacionadas a livre arbítrio a validade estatística de certo modo perde sua relevância, à medida que basta um caso que sirva de contra exemplo, para refutar a hipótese da inexistência do livre arbítrio. Em outras palavras, mesmo que se mostre um dia que $99,9 \%$ as pessoas no mundo não são livres, a existência de apenas uma pessoa que fosse livre refutaria a hipótese de que o livre arbítrio não existe. Estamos aqui diante de uma variação do problema da indução já aventado por Hume. No caso em questão, na pesquisa em questão, se não pode ser prevista a decisão para todas as pessoas envolvidas, abre-se a possibilidade de que nem todas as pessoas possam ter suas decisões previstas. Como podemos interpretar isto? Algumas pessoas são dotadas de livre arbítrio e outras não? Ou, mais plausivelmente, algumas pessoas são mais previsíveis que outras? Seja qual for a resposta o que não pode ser concluído, ou certamente não pode ser concluído com $100 \%$ de certeza, é que o livre arbítrio não existe. E mesmo que a não previsibilidade seja devida a imperfeição do equipamento, também não podemos afirmar que o melhoramento do equipamento irá necessariamente permitir a observação do comportamento preditivo em todos, pelo menos não até que o equipamento seja melhorado e as experiências sejam feitas. Até lá permanece a dúvida.

A conclusão que chegamos, então, até agora, é negativa, ou seja, concluímos que os estudos que analisamos não nos permitem concluir que o livre arbítrio não existe, e já que estes estudos estavam sendo aludidos para concluir que a neurociência prova que o livre arbítrio não existe, concluímos, então, que até o momento, não é verdade que a neurociência prova que o livre arbítrio é uma ilusão. Porém é importante ressaltar que nosso objetivo com isto não é, de modo algum, menosprezar o papel dos experimentos neurocientíficos na resolução de questões clássicas da filosofia. Muito pelo contrário, ressaltamos aqui que é fundamental que a filosofia esteja em plena sintonia com estes experimentos, e com o que nos ensina a experiência. Em relação ao livre arbítrio, fica claro que a filosofia não pode mais discuti-lo ao modo da metafísica dogmática, não crítica, que não leva em consideração nas análises o que a ciência e especificamente a neurociência tem a dizer sobre o tema. Parece, entretanto, que não só a filosofia pode tirar um enorme proveito dos trabalhos de neurociência como estes, por sua vez, também 
podem tirar proveito do rigor da análise conceitual filosófica. A filosofia pode não apenas apontar os problemas com algumas interpretações, atuando na direção da correção de rumos, mas pode também sugerir novos caminhos interpretativos e mesmo novos experimentos que possam ajudar a corroborar ou refutar clássicas ou novas hipóteses relacionadas não apenas ao livre arbítrio, mas também em relação a qualquer processo deliberativo, inclusive aqueles que envolvem escolhas morais.

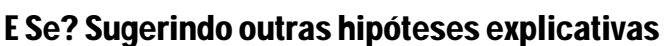

Em relação especificamente ao experimento que estamos discutindo, o chamado experimento de Libet revisitado, seu resultado objetivo mostra: a) que o cérebro pode começar a preparar inconscientemente suas decisões vários segundos antes que ela atinja a consciência, e b) que há uma série de processos cerebrais inconscientes que iniciam-se no córtex frontopolar e parietal. Estes resultados podem, entretanto, suscitar outras interpretações, bem diferentes da que vem sendo discutida e difundida, de que estes resultados corroboraria a ideia de que o livre arbítrio é uma ilusão. Gostaria de discutir aqui duas destas hipóteses, ressaltando, obviamente, que para a confirmação de qualquer uma delas mais experimentos seriam necessários.

1)A hipótese do consideration-generator (gerador de considerações) de Daniel Dennet.

Dennet ${ }^{14}$ propõe um modelo de decisão que ele descreve do seguinte modo:

Quando estamos diante de decisões importantes, um gerador de considerações, cujo resultado é em algum degrau indeterminado, produz uma série de considerações, algumas das quais podem ser imediatamente rejeitadas sendo consideradas irrelevantes pelo agente (consciente ou inconscientemente). Aquelas considerações que são selecionadas pelo agente como não desprezíveis figuram no processo de raciocínio, e se o agente é razoável estas considerações, em última instância, servem como fatores preditivos e explicativos da decisão final do agente.

14 DENNET, Daniel. Brainstorms. USA: Bradford Books, 1981, p. 295. 
Dennet procura aqui, como ele mesmo ressalta, resgatar a ideia de Russel de "seleção inteligente", significando isto pesar e rejeitar considerações que ocorrem ao sujeito, e entendendo este processo como sendo a inteligência fazendo a diferença. Inteligência que, lembra Dennet citando Russel, pode fazer coisas improváveis acontecerem. Dennet nos alerta aqui para um tipo de processo que teria duas fases, uma que envolve uma produção caótica e randômica, e outra que envolveria a seleção inteligente daquilo que nos interessa e que desejamos nesta massa de "inputs", a seleção inteligente daquilo que pode ser parcialmente arbitrário. Afirma Dennet que

quando alguém está diante de uma decisão importante, algo nele gera uma variedade de considerações mais ou menos relevantes que influenciam a decisão, algumas destas considerações estão determinadas a ser geradas, mas outras podem ser geradas de modo não determinístico.

Reescrevendo então o modelo de Dennet teríamos então, surgindo no nosso cérebro, uma série de inputs caóticos, dos quais não temos controle, e que podem surgir inconscientemente, e então, imediatamente nosso cérebro já faria a seleção daqueles que lhe interessam. Este modelo, me parece, pode descrever o que acontece não apenas em grandes decisões, mas mesmo em decisões bem menos complexas como, por exemplo, escolher com qual das nossas mãos apertaríamos um botão. $\mathrm{O}$ que Dennet sugere no seu modelo para explicar decisões importantes é que exatamente quais considerações ocorrem as pessoas em determinada circunstância é totalmente indeterminado, e assim seria impossível prever decisões a não ser condicionalmente, ou seja, transpondo para o experimento, se considerações A, B, C ocorrerem a um sujeito ele escolherá apertar o botão com a mão direita e se considerações D, E, F ocorrerem ele apertará o botão com a mão esquerda. Porém observe que ainda que não saibamos quais são estas considerações, através do fMRI elas podem ser lidas em termos de padrões de ativação neuronais. Se observamos, por exemplo, que a maioria das pessoas que decidem apertar o botão A (direito) apresentam um padrão de atividade neuronal X no FPC, podemos prever, para um outro conjunto de pessoas que quando o padrão X aparecer no FPC, elas provavelmente escolherão A (botão direito), e se isso acontecer, digamos, em 60\% dos casos, temos ai um padrão preditivo. Isto, parece, não significaria que as pessoas não são livres, mas sim corroboraria o modelo de Dennet do gerador de considerações indicando que 
a geração de um conjunto de considerações $C$, ou um modo $C^{\prime}$ de organizálos e rejeitá-los seria preditivo do comportamento A (embora não necessariamente implique $A$ ), enquanto um conjunto de considerações $D$ ou um modo D' de organizá-lo seria preditivo do comportamento B (embora não necessariamente implique $B$ ). Esta hipótese seria bem mais modesta, mas não menos interessante e importante, porque corroboraria um modelo explicativo básico do mecanismo pelo qual realizamos escolhas, e o entendimento deste mecanismo é uma das grandes preocupações e um dos grandes objetivos da pesquisa em neurociências. Já nos adverte Haynes, sugerindo futuras pesquisas, que inicialmente parece implausível que decisões rápidas e responsivas poderiam ser previstas, alertando que seria impossível dirigir o carro em ruas movimentadas se levássemos 7 segundos para tomar decisões. Entretanto ele alerta para o fato de que mesmo decisões rápidas provavelmente sejam determinadas por padrões cognitivos ou "políticas" do nosso cérebro que permanecem por um tempo muito maior do que os 7 segundos. A investigação da existência destes padrões é objeto da neurociência, mas a filosofia tem ai um papel fundamental estabelecendo modelos que poderiam ser confirmados ou refutados pela experiência, e o modelo de Dennet do "gerador de considerações" poderia ser um destes modelos a ser testado.

\section{2)A vontade humana e o livre arbítrio começam em $\mathrm{BA} / 10$ ?}

As pesquisas que discutimos apontam a área descrita como BA/10 como peça chave no processo de decisão. Se formos resumir os resultados objetivos da pesquisa que mencionamos os resultados seriam os de que esta região cerebral (O FPC) é a região que exibe os primeiros sinais antes do movimento voluntários. No experimento que discutimos foi observado que na região há uma mudança no padrão do sinal relativo ao modo como a escolha é feita, ou seja, há um padrão de sinais para a escolha $\mathrm{A}$ e outro para a escolha B. Os resultados, como dissemos, foi corroborado no experimento de Bode ${ }^{15}$ que nos diz que o "estudo corrobora a hipótese que o córtex frontopolar é uma região chave para decisões livres”. Há outros artigos que

${ }^{15}$ BODE et all, Op. cit. 
discutem outras funções para BA $10^{16}$ como a de que o sinal presente no FPC, embora simples, promove o aprendizado de que tipo de metas e processos de geração de metas produzem custos e benefícios particulares, melhorando nossas escolhas futuras.

Esta possibilidade, de que o córtex frontopolar esteja envolvido na tomada de decisões e que ali se encontrem os primeiros sinais de padrões preditivos de ações nos permite especular se, ao contrário das interpretações correntes, que estabelecem que estes estudos questionariam o livre arbítrio, não seria exatamente o inverso disto e o FPC não seria, na realidade, uma área cerebral de extrema importância para entendermos o que costumamos chamar de vontade humana, ocorrendo ali os momentos iniciais do processo de manifestação da vontade, ainda que de forma inconsciente, culminando com a realização livre da ação, envolvendo em algum momento deste processo, a consciência da intenção. Se assim for, aquilo que se chama de vontade, na realidade seria a descrição de um processo cerebral, que inicia inconscientemente em nós, envolvendo nossa história de vida, nossos desejos mais profundos, nossos medos e frustrações, que de alguma forma são retidos pelo nosso cérebro, se tornam conscientes, ou não, e nos levam à ação. Se assim for, um antigo problema na determinação da moralidade das ações já aventado por Kant, ou seja, a incognoscibilidade das nossas intenções ${ }^{17}$ ou seja, o fato de que nem mesmo nós temos total consciência da motivação de nossas ações, o que impede que sejamos capazes de determinar com total certeza se uma ação é ou não moral, pode começar a ser compreendido pela neurociência. Isso não seria o fim do livre arbítrio, mas ao contrário, daria aos homens um conhecimento muito maior de si próprios, conhecimento este que já Platão com suas formulações do "conhece-te a ti mesmo"18 estabeleceu como sendo umas das maiores e mais importantes empreitadas filosóficas. Este conhecimento traria aos homens a possibilidade de cada vez mais nos tornarmos senhores de nossos destinos, e portanto, de nos

\footnotetext{
16 Ver, por exemplo, TSUJIMOTO, S; GENOVESIO, A; WISE, S. P. "Frontopolar Córtex: encoding ends at the end of the endbrain". In: Trends Cogn Science, v. 15, 4, 2011, p. 169-76, que afirmam que o sinal presente no FPC, embora simples, promove 0 aprendizado de que tipo de metas e processos de geração de metas produz custos e benefícios particulares, melhorando escolhas futuras. Mas o que nos interessa aqui é discutir a possiblidade de que o córtex frontopolar esteja envolvido na tomada de decisões e que ali se encontrem os primeiros sinais de padrões preditivos de ações.

17 KANT, I. Groundwork of the Metaphysics of Morals. Cambridge: Cambridge University Press, 1997.

${ }^{18}$ A máxima está escrita na entrada do templo de Apolo em Delfos na Grécia. Platão discute o uso da expressão e seu significado em vários dos seus diálogos, através de Sócrates.
} 
tornarmos seres cada vez mais livres, diminuindo ou mesmo eliminando a influência de fatores indesejáveis em nossas escolhas. Ao invés, então, de provar que o livre arbítrio não existe, os experimentos aventados podem, na realidade, apenas estar sugerindo que não sabemos tudo de nós mesmos, abrindo assim uma porta enorme para que venhamos a investigar nossas motivações, mesmo as que nos parecem mais ocultas, através da neurociência, possibilitando assim que venhamos a nos conhecer melhor, a fim de que nos tornemos mais, e não menos livres.

Finalizando, então, retomando a discussão sobre a vontade humana e sobre o livre arbítrio, resguardando a terminologia metafísica, podemos especular que começamos a decidir livremente em BA 10, ou que, só somos livres porque somos dotados, como espécie, de um cérebro com um córtex frontopolar altamente evoluído e que permite que manifestações inconscientes apareçam no início do processo decisório, levando no final da cadeia, à decisão, à consciência da decisão e à ação, sendo que em relação à decisão e a consciência da decisão a ordem temporal não necessariamente é essa.

Concluindo então, afirmamos que se há, pois, uma ilusão a ser discutida, esta não é a de que o livre arbítrio existe, e sim, a de que o livre arbítrio existe independentemente do nosso cérebro. Somos o que somos, e somos livres, porque nosso cérebro evoluiu para ser o que é hoje, em um processo que levou milhares de anos. Aqui me parece que podemos dar a palavra final a Dennet, que nos diz ${ }^{19}$ :

A liberdade humana é mais jovem que a espécie. Seus aspectos mais importantes têm apenas muitos milhares de anos, um piscar de olhos na história da evolução, mas que neste curto espaço de tempo tem transformado o planeta de um modo tão significativo quanto as grandes transições biológicas como a criação de uma atmosfera rica em oxigênio e a criação da vida multicelular. A Liberdade teve que evoluir como qualquer outro aspecto da biosfera e ainda continua hoje evoluindo. A Liberdade é real agora em algumas partes felizes do mundo, e aqueles que a amam, sabiamente a amam. Mas ela está longe de ser inevitável, e longe de ser universal. Se entendermos melhor como a liberdade acontece podemos trabalhar melhor para sua futura preservação e proteção.

19 DENNETT, Daniel. Freedom Evolves. New York: Penguin Group, 2003, p. 305. 


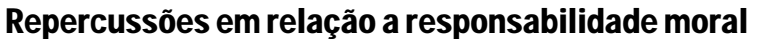

Pelo que aqui vimos a neurociência não prova que o livre arbítrio não existe, e isto nos dá um grande alento, ou seja, as descobertas da neurociência não afetam a nossa intuição básica de que somos livres e portanto responsáveis pela maioria dos nossos atos. Tivesse a neurociência provado que o livre arbítrio é uma ilusão, como muitos acreditam, e teríamos que promover uma verdadeira revolução nas nossas ideias de responsabilidade moral e legal, mas, felizmente parece que não é o caso. Entretanto, algumas pesquisas na área de neurociência da ética parecem nos indicar que a neurociência da ética tem sim muito a nos dizer e a nos ensinar sobre responsabilidade moral.

Por exemplo, o relatório da Royal Society Britânica sobre as relações entre neurociências e a lei ${ }^{20}$ aponta que evidencias de fMRI sugerem que há diferenças entre os cérebros de pessoas diagnosticadas como psicopatas e outras, e também evidências de componentes hereditários na psicopatia. Mas então, perguntam os autores do relatório, isto significa que os psicopatas deveriam ter suas penas reduzidas, já que seriam menos responsáveis por seus atos, ou ao contrário, significa que deveriam ser submetidos a tempos maiores de prisão em nome da segurança pública?

Questões como estas surgem também em outro importante estudo ${ }^{21}$ sobre violência que também remete para a questão da responsabilidade moral. No estudo é testada a hipótese que indivíduos com cavum septum pellucidum (CSP), um marcador de mau desenvolvimento límbico neural, mostram níveis mais altos de psicopatia e comportamento antissocial. Os resultados apontam que indivíduos com CSP tem uma probabilidade maior de apresentar personalidade antissocial, psicopatia, e condenações do que aqueles que não apresentam CSP. Os autores concluem que se algumas ofensas sérias tem, em parte, origem neurológica, a prevenção deveria começar no período pré-natal, e referem-se a programas de prevenção realizados nos EUA e que foram eficazes, como um programa pré-natal focado na saúde materna que implicou na redução da delinquência juvenil 15 anos depois. Este programa foi focado na redução de fumo e álcool durante a

\footnotetext{
20 The Royal Society, Neuroscience and the law , Brain Waves Module 4, 2011, p.14.

${ }^{21}$ RAINE, Adrian; LEE, Lydia; YANG, Yaling; COLLETTI, Patrick. "Neurodevelopmental marker for limbic maldevelopment in antisocial personality disorder and psychopathy". In: British Journal of Psychiatry, 197, 2010, p.186-192.
} 
gravidez, já que abuso de álcool e fumo neste período são associados com CSP. Apontam também os autores para uma intervenção experimental que melhorou o ambiente de crianças de 3 a 5 anos com alimentação melhor, mais exercícios físicos e estimulação cognitiva e que resultou na melhoria do desenvolvimento cerebral das crianças até a idade de 11 anos, e redução das ofensas criminais até a idade de 23 anos.

Os resultados deste estudo sobre a violência, penso, mostram que certas más formações cerebrais poderiam predispor ou inclinar para determinados comportamentos disfuncionais, mas não determinam absolutamente estes comportamentos, e várias intervenções ambientais podem ser feitas tanto a fim de evitar estas formações ainda no período de formação do feto, quanto no período da infância a fim de minimizar suas consequências. Deste modo haveria tanto a responsabilidade da sociedade e dos governos para com estes indivíduos, no sentido de realizar programas da saúde preventivos, quanto uma diminuição da responsabilidade moral destes indivíduos que não significa, entretanto, isenção completa de responsabilidade.

Um outro caso importante de ser analisado foi discutido por Patrícia Churchland ${ }^{22}$, relatando que um homem de meia idade no estado da Virginia com nenhuma história de mau comportamento começou a molestar sexualmente sua filha adotiva de 8 anos de idade, e seu comportamento começou a se mostrar obsessivo. Após reclamação constante de dores de cabeça e vertigem ele foi levado para exames em seu cérebro e foi descoberto um enorme tumor benigno na área frontal de seu cérebro, invadindo o septum e o hipotálamo, regiões que são conhecidas por regular o comportamento sexual. Depois de ter seu tumor removido seu interesse sexual voltou ao normal. Entretanto, alguns meses mais tarde seu apetite sexual por crianças voltou e um novo exame no cérebro revelou que o tumor havia retornado. Churchland observa que estes casos levantam o tema do livre arbítrio, e faz os seguintes questionamentos: Este homem possui livre arbítrio? Ele era responsável por seu comportamento? Pode um tumor destruir o livre arbítrio? Considerando que desejos sexuais são regulados por hormônios que agem no septum e em áreas conexas, o quão diferente somos todos nós do homem de Virgínia?

${ }^{22}$ CHURCHLAND, Patrícia. "Do we have free will", Op. cit. 
Temos aqui uma questão da ética da neurociência que nos remete diretamente à questão da responsabilidade moral: $\mathrm{O}$ "homem da Virgínia" era ou não responsável por seus atos? Se não era responsável, como puni-lo? E tem o Estado o direito de exigir que as pessoas se submetam a exames cerebrais para comprovar se estas estão agindo "livremente" ou não? O que dados advindos de pesquisas neurocientíficas, como este exemplo do pedófilo de Virginia, e das pesquisas sobre violência com o CSP podem nos ensinar? Embora não mostrem que não temos livre arbítrio, mostram que há determinadas condições que limitam o exercício do nosso livre arbítrio, e fazem com que algumas de nossas ações não sejam voluntárias, consequentemente limitando nossa responsabilidade moral como já descrevia Aristóteles. Com isso o que então muda com a neurociência? Sugiro que a neurociência promove três tipos de transformações importantes:

1) Amplia a compreensão e a descrição das circunstâncias que limitam nossa liberdade e por consequência, nossa responsabilidade moral, mostrando que há mais casos aonde nos enganamos na determinação da existência de uma escolha livre do que supúnhamos.

2) Auxilia na determinação de probabilidades de comportamento devido a certas circunstâncias biológicas que independem do agente, ou que não são controláveis pelo agente, e que desconhecíamos.

3) Auxilia aqueles que assim desejarem a recuperar a sua liberdade de escolha, como em casos graves de Alzheimer e demência, nos quais as pessoas perdem completamente as suas faculdades mentais, e casos como o mencionado, do pedófilo de Virgínia

A neurociência, e particularmente a neurociência da ética, então, não ameaça a noção de responsabilidade moral e legal, ao contrário, ela pode ser usada como mais um elemento capaz de promover a justiça, evitando a que venhamos a responsabilizar aqueles que não podem ser responsabilizados, e com isso refinando a responsabilização moral e criminal na sociedade, de modo que venhamos a caminhar na direção de um mundo no qual a responsabilidade moral, a culpabilidade e também a punição sejam atribuídas apenas aqueles que a mereçam. O objetivo disto não é estabelecer uma sociedade na qual não se responsabiliza moralmente as pessoas, mas sim, uma sociedade aonde se atribui responsabilidade de forma justa. A neurociência da ética também nos promete, para o futuro, que sejamos 
capazes de descobrir se as alegações dos indivíduos de condições atenuantes para suas ações são de fato legítimas ou não, evitando que também deixem de ser responsabilizados e punidos aqueles que merecem sê-lo. A neurociência pode assim contribuir para a construção de um mundo mais livre, já que ao ampliar o conhecimento das condições naturais e das circunstâncias que limitam o nosso livre arbítrio, ela nos promete, também, a possibilidade de descobrir mecanismos capazes de combater e até evitar estas condições e circunstâncias.

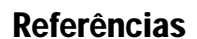

BODE, S.; HANXI HE, A.; SOON, C. S.; TRAMPEL, R.; TURNER, R.; HAYNES, J. D. "Tracking the Unconscious Generation of Free decisions Using Ultra-High Field fMRI”. In: Plos One, vol. 6, n. 6, 2011, p.1-13.

CHURCHLAND, P. “Do we have free will?”. Disponível em: http://philosophyfaculty.ucsd.edu/faculty/pschurchland/papers/newscientist 06dowehavefreewill.pdf\#page=1\&zoom=auto,0,800. Acessado em 31/10/2013 de New Scientist.com News service.

DENNET, D. Brainstorms. USA: Bradford Books, 1981. . Freedom Evolves. New York: Penguin Group, 2003.

HAYNES, J. D. "Decoding and predicting intentions". In: Ann. N.Y. Acad. Sci., 1224, 2011, p. 9-21.

KANT, I. Groundwork of the Metaphysics of Morals. Cambridge: Cambridge University Press, 1997.

KEEFNER, K. Free Will. A Response to Sam Harris. Kindle edition: 2012.

NAHMIAS, E. "Scientific Challenges to Free Will". In: O'CONNOR, Timothy e SANDIS, Constantine (ed). A Companion to the Philosophy of Action. UK: Blackwell, 2010, p. 345-356.

RAINE, A.; LEE, L.; YANG, Y.; COLLETTI, P. “Neurodevelopmental marker for limbic maldevelopment in antisocial personality disorder and psychopathy”. In: British Journal of Psychiatry, 197, 2010, p.186-192.

ROSKIES, A. "Neuroscientific challenges to free will and responsibility". In: Trends in Cognitive Sciences, vol.10, n.9, 2008, p. 419-423.

SOON, C.; BRASS, M.; HEINZE, H.-J.; HAYNES, J. D. "Unconscious determinant of free decisions in the human brain”. In: Nature, vol. 11, n. 5, 2008, p. 543-545. 
TSUjIMOTO, S; GENOVESIO, A; WISE, S. P. "Frontopolar Córtex: encoding ends at the end of the endbrain”. In: Trends Cogn Science, v. 15, 4, 2011, p. $169-76$.

Email: cinaranahra@hotmail.com

RECEBIDO: Novembro/2013

APROVADO: Novembro/2013 